\title{
AS INFLUENCERS DIGITAIS E A AUTOIMAGEM COMO PRODUTO DE COMPORTAMENTO DE CONSUMO
}

\section{RESENHA}

ABREU, Liliane Alcântara de 1, MELO, Natalia Sayuri 2, SOARES, Pamela Cristina ${ }^{3}$, NUNES, Letícia Monteiro ${ }^{4}$, SILVA, Gabriella Braga Dias da 5, MENDES, Matheus Passos ${ }^{6}$

ABREU, Liliane Alcântara de. Et al. As influencers digitais e a autoimagem como produto de comportamento de consumo. Revista Científica Multidisciplinar Núcleo do Conhecimento. Ano. 07, Ed. 01, Vol. 05, pp. 05-33. Janeiro de 2022. ISSN: 24480959, Link

acesso: https://www.nucleodoconhecimento.com.br/psicologia/comportamento-deconsumo

1 Especialista em Neurociência Pedagógica pela AVM Educacional/UCAM/RJ; especialista em Arteterapia em Educação e Saúde pela AVM Educacional/UCAM/RJ; especialista em Pesquisa de Comportamento e Consumo pela Faculdade SENAI CETIQT RJ; especialista em Artes Visuais pela UNESA/RJ; bacharela em Design pela Faculdade SENAI CETIQT RJ. Bacharelanda em Psicologia pela UNIP/SP.

${ }^{2}$ Bacharela em Comunicação Social pela Faculdade Casper Libero/SP. Bacharelanda em Psicologia pela UNIP/SP.

${ }^{3}$ Bacharelanda em Psicologia pela UNIP/SP.

${ }^{4}$ Bacharelanda em Psicologia pela UNIP/SP.

${ }^{5}$ Bacharelanda em Psicologia pela UNIP/SP.

${ }^{6}$ Bacharelando em Psicologia pela UNIP/SP.

RC: 105379

Disponível em: https://www.nucleodoconhecimento.com.br/psicologia/comportamento-deconsumo 


\section{RESUMO}

Este artigo é resultado de um estudo de Psicologia com enfoque no comportamento dos indivíduos nomeados influenciadores digitais e seus seguidores. O problema norteador fixou-se na questão: o que leva sujeitos a serem suscetíveis às mudanças de seus comportamentos mediante o comando de alguém desconhecido? Assim, o objetivo geral se concentrou em como ocorre a atuação dos influencers nos espaços virtuais e seu impacto no comportamento dos indivíduos que os acompanham. As hipóteses tiveram o pressuposto de que os influenciadores necessitam criar e manter conceitos de felicidade; para isto suscitam formas de se expor, com isso, muitos indivíduos, na sociedade contemporânea, estão desenvolvendo doenças psíquicas, devido a essa necessidade de exposição. Como método, a pesquisa se fundamentou na observação e análises de seis influenciadoras brasileiras do gênero feminino, nas faixas etárias dos 20 aos 25 anos e dos 35 aos 40 anos, observando seus estilos de vida, assuntos abordados e os comentários produzidos pelos apoiadores e haters (expressão estrangeira que define usuários na internet que propagam discursos de ódio). Igualmente foi efetuada a revisão bibliográfica para a discussão teórica sob a luz de alguns estudiosos para compreender e explicar esse fenômeno. Como resultados e conclusões, percebeu-se que muitas influenciadoras, seguidores e até mesmo os haters estariam em simbiose com o narcisismo, o medo da exclusão, invisibilidade e a busca pela plena felicidade. Por outro lado, foi possível detectar que outras influenciadoras produzem informações de acréscimo social de forma útil e positiva.

Palavras-chave: Comportamento, Influenciadores, Digital, Psicologia, Sociedade.

RC: 105379

Disponível em: https://www.nucleodoconhecimento.com.br/psicologia/comportamento-deconsumo 


\section{INTRODUÇÃO}

O fenômeno escolhido pelos autores deste artigo para a realização das observações foi influenciadores digitais. Também conhecidos como digital influencers, influencers ou criadores de conteúdo, que são pessoas que possuem a capacidade de sugestionar através de seus discursos a vida de outras pessoas, na tomada de decisões de como agir, pensar, viver, e principalmente consumir. Esses influenciadores usam as redes sociais (Facebook, Twitter, Instagram, Youtube, Tiktok) como meio de se comunicar com seus seguidores e utilizam essas plataformas para discutir temas do dia a dia e até pautas sociais como política, feminismo, racismo e gordofobia. Além disso, é através de suas redes que eles influenciam e incentivam o consumo, seja de conteúdo, produtos ou ideais.

Tal fenômeno foi escolhido pelo grupo, pois houve um interesse em compreender como é este novo mercado de influenciadores digitais e como esses sujeitos podem atingir outras pessoas, no caso as mulheres, que consomem suas publicações. Logo, houve a necessidade de se responder o problema norteador: o que leva sujeitos a serem suscetíveis às mudanças de seus comportamentos mediante o comando de alguém desconhecido?

Portanto, o objetivo geral se concentrou na atuação dos influenciadores digitais nos espaços virtuais e seu impacto no comportamento dos indivíduos que os acompanham. Como consequência, os objetivos específicos se expandiram na compreensão de como o influenciador atua diante de seu público-alvo; em assimilar como a atuação do influenciador pode induzir os processos de consumo, e entender quais são os impactos no comportamento dos indivíduos que aceitam ou rejeitam os conteúdos dos influencers.

Para tanto, a equipe elaborou pressupostos para três hipóteses que pudessem ser confirmadas ou refutadas ao final da pesquisa: os influenciadores digitais necessitam RC: 105379

Disponível em: https://www.nucleodoconhecimento.com.br/psicologia/comportamento-deconsumo 
criar e manter conceitos de felicidade; suscitam novas e intensas formas de se expor como um produto de consumo, e muitos indivíduos na sociedade estão desenvolvendo massivamente adoecimentos psíquicos como, por exemplo, o narcisismo exacerbado devido à alta necessidade de exposição.

O ponto central de observação se manteve essencialmente no fenômeno da figura do influenciador digital. A partir dessa perspectiva a equipe fez o levantamento do conteúdo produzido no Youtube e Instagram de seis influenciadoras brasileiras, nas faixas etárias dos 20 aos 25 anos e dos 35 aos 40 anos. Observou-se as apresentações realizadas, modos de vida, assuntos abordados e os comentários produzidos pelos seguidores e hatters, em sua maioria, mulheres.

A fundamentação teórica, foi obtida pela análise dos pensadores: Michel Foucault (2001; 2019), com o apoio de Cecília Coimbra e Maria Livia Nascimento (2001) sobre os princípios da exclusão e julgamentos do outro socialmente. Pierre Bourdieu (2007) e Mary Douglas e Baron Isherwood (2009) trazem por meio de breve apoio de Liliane Abreu (2013), a perspectiva antropológica dos padrões sociais para explicar o sistema de consumo. Esse conteúdo também é ampliado pelas proposições de reforço por Zygmunt Bauman (2008a; 2008b; 2009) e William Baum (2019), que discorrem sobre os medos para silenciar (e afrontar) muitos indivíduos, ou dar voz àqueles que manipulam em massa para comportamentos de ódio e alienantes. Han Byung-Chul (2018) dá o entendimento sobre o fenômeno do cancelamento (termo utilizado na internet para excluir indivíduos, que apresentam comentários ou atitudes consideradas ofensivas socialmente). Burrhus Skinner (2000), Robert Hall (1975), Márcio Moreira e Carlos Medeiros (2007), mostram como ocorrem os processos de likes e deslikes. Marilene Chaui $(2011 ; 2012 ; 2017)$ embasa a inversão de discursos, a realidade, e como a apropriação ideológica de discursos se encaixa também nos comportamentos narcísicos pela visão psicanalítica clínica de Sigmund Freud (1972; 2011), Jacques Lacan através de Vladimir Safatle (2007) e David Zimerman (2004).

RC: 105379

Disponível em: https://www.nucleodoconhecimento.com.br/psicologia/comportamento-deconsumo 
Como isso se relaciona e fundamenta a intensa necessidade de reforçadores nos indivíduos para concretização de suas utopias no universo contemporâneo virtual, é o que será apresentado neste artigo.

\section{PROCEDIMENTOS}

As observações, estudos conceituais e análises para entendimento dessa temática social contemporânea do fenômeno conhecido como influenciadoras digitais, ocorreu no segundo semestre (agosto a novembro) de 2020 como parte de um trabalho acadêmico do curso de Psicologia, para a Universidade Paulista-UNIP/SP.

Dois membros da equipe ficaram encarregados de observar dez (dez para cada membro) postagens de uma influencer (mulheres cisgênero) entre 20 a 25 anos e a interação com seus seguidores. Dois membros da equipe ficaram encarregados de observar dez (dez para cada membro) postagens de uma influencer (mulheres cisgênero) entre 35 a 40 anos e a interação com seus seguidores. Dois membros da equipe ficaram encarregados de observar cinco postagens de uma influencer (mulher cisgênero) entre 35 a 40 anos, e, cinco postagens de uma influencer (mulher transgênero) entre 20 a 25 anos; observando ainda a interação com os seguidores de ambas. Assim dividido, foram observados ao todo seis influencers conhecidas das mídias digitais: Gabriele Pugliese, mantida a identificação como G.P.; Gabriela Loran identificada como G.L.; Lorrane Silva identificada como L.S. (mas, em outros momentos, pode aparecer como P.Q., por seu apelido de Pequenalo); Ellora Hoanne será identificada como E.H.; Talene Gulusian que será identificada como T.G.; Maíra Medeiros representada pela letra $M$. No momento das observações e análises, as influencers apresentavam os seguintes dados:

Gabriela Pugliesi é uma mulher de 35 anos, branca, loira, rica e de família originalmente já abastada. É a influencer de sexo feminino com muito seguidores virtuais no Brasil, possuindo um canal no Youtube (703 mil inscritos), e ainda atua em RC: 105379

Disponível em: https://www.nucleodoconhecimento.com.br/psicologia/comportamento-de$\underline{\text { consumo }}$ 
plataformas como Instagram (4.200.000 inscritos) e Facebook (111.958 inscritos). Nessa última, ela se apresenta como "Influenciadora digital e empresária; estreou suas redes sociais em 2013 (...). Em seu canal no YouTube, recebe e entrevista personalidades em seu programa 'Vendi Meu Sofá'”.

Gabriela Loran é uma mulher transsexual de 24 anos, atriz (a primeira atriz trans do programa televisivo Malhação). Ela possui um canal no Youtube (9.530 inscritos), e ainda atua em plataformas como Instagram (55.600 inscritos) e Facebook (1.586 inscritos).

Lorrane Silva tem 24 anos. Nasceu com uma síndrome ainda desconhecida pelos médicos que compromete seus membros inferiores. A influencer utiliza muletas para locomoção. Possui seguidores no Instagram (4.300.000 de inscritos) e na rede social Tik Tok (mais de 5 milhões de inscritos). Ela utiliza suas redes para tratar com humor acerca da sua vida e suas dificuldades diárias.

Ellora Hoanne tem 25 anos e possui um canal no YouTube (1.410.000 inscritos) e conta no Instagram (527 mil inscritos). É autora do livro "Por todas nós: conselhos que não recebi sobre luta, amor e ser mulher". Em suas redes produz conteúdos sobre feminismo, sexualidade, relacionamentos, autoconhecimento, autoestima, entre outros.

Talene Gulusian é uma influenciadora digital de 35 anos. Mãe de três filhos, sendo os dois primeiros de pais diferentes e a caçula fruto de fertilização in vitro. Possui um canal no Youtube (434 mil inscritos) e no Instagram (277 mil inscritos), onde além de dividir sua vida através dos stories, também realiza publicidades e divulgações. Ela, também, possui alguns canais secundários menores e administra a página do Instagram de sua loja de pijamas, chamada La Bella Plume (9.193 inscritos).

RC: 105379

Disponível em: https://www.nucleodoconhecimento.com.br/psicologia/comportamento-deconsumo 
Maíra Medeiros possui um canal do YouTube intitulado "Nunca Te Pedi Nada" (1 milhão de inscritos). A criadora de conteúdo é formada em Publicidade e Propaganda, deu aulas de inglês por mais de dez anos e foi editora de conteúdo para web de outros criadores. Começou o canal por acreditar que temas como empoderamento feminino e aceitação eram pouco falados e mereciam ser abordados. Além disso, atua na plataforma do Instagram (741 mil seguidores).

Os pontos que foram observados por cada integrante da equipe:

- Da influencer: como ela se apresentava; o que vendia como estilo de vida; como se portava e se comunicava; o que dizia como referência de como seus seguidores deviam se comportar, consumir ou o que fazer.

- Dos seguidores: como interagiam; como se comunicavam; como se comportavam; como se apresentavam; o que consideravam como importante em suas vidas a partir dessa interação com a influencer.

Como os membros do grupo realizaram observações com influenciadoras diferenciadas, a dupla notou três principais destaques potenciais: 1- estilo de vida (vida pessoal, humor, estilo de vida/rotina); 2- questões sociais atuais (padrão estético/beleza, machismo, desconstrução, discursos de ódio); e 3 - consumo (de si, do outro, de produtos e de publicidades). É importante salientar que esses pontos mais constatados em maior frequência se entremeiam e ao mesmo tempo se distanciam uns dos outros, em uma constante dicotomia. Portanto, precisaram ser vistos simultaneamente como aspectos independentes e globais dentro do mesmo fenômeno. Exatamente por isso, a equipe acabou tendo que subdividir em categorias essa análise inicial, até para ordenar e entender com o que estava se deparando. Ademais, as influencers escolhidas não abrangiam um ponto em comum de conteúdo, como, por exemplo, todas falarem sobre a condução (alienante) da estética de beleza, ou política, ou qualquer outro assunto comum entre todas. Cada uma das

RC: 105379

Disponível em: https://www.nucleodoconhecimento.com.br/psicologia/comportamento-de$\underline{\text { consumo }}$ 
influenciadoras digitais abordava pautas diferenciadas, que nos levaram à indagação inicial: Por que tanta gente segue e faz o que essas influencers dizem, mesmo elas sendo diferentes? "o que essas diferenças podem ter em comum?" e "o que poderia unir essas influencers tão fortemente a esses seguidores?"

\section{DISCUSSÃO}

Para a elaboração deste artigo, o grupo se deparou com vários tópicos dicotômicos, mas com pontos mais perceptíveis e constantes no conjunto total sobre a subjetividade e os comportamentos sociais que eram análogos. Alguns desses pontos se apresentavam na necessidade do sujeito de ser visto, amado (até idolatrado em alguns casos), e reconhecido pela autoimagem. Além disso, a materialização de discursos de ódio, instantaneidade e obsolescência das relações foram aspectos em comum, seja nas influencers, seja nos seguidores, funcionando como uma simbiose, ou seja, como uma dependência emocional do outro. Portanto, as observações dessas diferentes influenciadoras desencadearam a percepção dos três principais agrupamentos comportamentais que constituíram essa discussão teórica: o estilo de vida (vida pessoal, humor, estilo de vida/rotina); questões sociais atuais (padrão estético/beleza, machismo, desconstrução, discursos de ódio); e consumo (de si, do outro, de produtos e de publicidades). Todos, contudo, são aspectos independentes e globais dentro do mesmo fenômeno de aceitar ser influenciado por alguém e não elaborar suas próprias conviç̧ões.

A subjetividade humana pode ser entendida como produto resultante de todas as experiências que alguém tenha com o mundo e que afetam esse indivíduo. Michel Foucault (2001; 2019; apud COIMBRA; NASCIMENTO, 2001) em História da loucura, compreende a subjetividade como modo de vida. Enquanto corpo e mente, esse sujeito relaciona-se com tudo e todos, suscitando a partir disso, a retenção, reação e até a criação de interações de seu tratamento vindo da sociedade. Logo, as

RC: 105379

Disponível em: https://www.nucleodoconhecimento.com.br/psicologia/comportamento-deconsumo 
transformações positivas ou negativas que ocorrem em alguém, surgem como marcas individuais e relacionadas ao meio social, refletindo-se ainda em seus comportamentos. Foucault igualmente aponta que esse mecanismo sociocultural origina discursos distorcidos e uma plateia que classifica, condena e perpetua certas práticas institucionalizadas de degradação daqueles em situação de invisibilidade.

Nesse cenário, o advento do ano 2.000 (d.C.) da atual contemporaneidade acelerou as potencialidades tecnológicas que já vinham surgindo em décadas anteriores. Com isso, a internet se popularizou e trazendo com ela as redes sociais. A união dessas redes sociais e a possibilidade tecnológica de produção de vídeos pessoais por meio dos aparelhos celulares, desencadeou a alta exposição dos indivíduos em busca da aprovação dos chamados likes. Um processo como o que Skinner (2000) mostrava em suas cobaias de interação com ambiente através de estímulo e reforço, e que não podemos ser imaturos em desprezar esses estudos, mesmo sendo de outras linhas antagônicas na própria área da Psicologia.

Os sujeitos são gradativamente modelados, para causar uma nova resposta de comportamento, e recebendo o reforço das curtidas ou likes. O excesso de vídeos, na maioria, mas com material de postagens diversas, incluindo por meio da escrita alcança o reforço pela resposta imediata, proporcionada pelos likes, criando assim, uma grande motivação para a continuidade de produção de postagens. Seja como for, a continuidade dessa estimulação compreendida como positiva, promove em termos emocionais, uma euforia nos sujeitos, tornando o universo virtual extremamente sedutor. Assim, de maneira geral, os indivíduos podem ter reações emocionais variadas pela subjetividade e histórico de cada um, indo de euforia (quando recebem as curtidas), frustração e raiva (quando ignorados ou contrariados), e/ou imediatismo constante (não suportando a demora de respostas de terceiros em interlocuções). E isso se estende aos sujeitos que interagem na forma de seguidores, sobretudo quando, por exemplo, uma celebridade fala em vídeo o nome de alguém

RC: 105379

Disponível em: https://www.nucleodoconhecimento.com.br/psicologia/comportamento-deconsumo 
desconhecido que o segue ou responde por escrito, pois as pessoas tendem a reagir com grande emoção, demonstrando comportamentos de euforia. Outros que acompanham esse acontecimento, criam a expectativa de que o mesmo ocorra com eles, constituindo uma engrenagem consecutiva de reforçadores positivos.

Conforme Hall (1975), o reforçamento é tudo aquilo (evento ou consequência de estímulo) que aumenta a força ou a probabilidade de ocorrência de um determinado comportamento se repetir, ou seja, o comportamento produz consequências e é controlado por elas. Elogios, bonificações e outras ações aplicadas logo após (de imediato) uma ação que se deseja, atuam como reforço de comportamento e com efeito máximo. Quanto mais rápido e imediato for o reforço em um comportamento desejado, mais eficaz ele se torna, como o advento das curtidas. Moreira e Medeiros (2007) citam que reforços naturais, como elogios e comportamento de admiração são extremamente poderosos. Assim, o reforçamento contínuo em uma frequência alta, tende a deliberar a satisfação no indivíduo e a expectativa de querer mais.

As plataformas digitais como o Facebook, Instagram e Youtube, por exemplo, têm se modificado cada vez mais para fornecer maiores recursos na tentativa de diversificar a maneira que os conteúdos podem ser criados, conduzindo a uma maior permanência de tempo dos seus membros. É importante compreender que esses recursos não são criados sem motivo, mas sim, são estratégias para diversificar as possibilidades de uma empresa difundir suas publicidades, dando espaço e ferramentas para que eles consigam deixar cada vez mais natural a divulgação de algum produto ou serviço. Ademais, isso alcança uma personagem que surgiu fortemente nos últimos dez anos: o influenciador digital ou influencer.

Nos livros A arte da vida e Vida para consumo, Bauman (2009; 2008b) pondera que para entender a dinâmica do universo virtual e seus fenômenos, antes faz-se necessário compreender que existem estruturas geracionais que sofrem influência

RC: 105379

Disponível em: https://www.nucleodoconhecimento.com.br/psicologia/comportamento-deconsumo 
dos modos de vida de seus tempos, muito antes das manipulações de condução mercadológica. Desta forma, ele observa que a visão de mundo para as pessoas atuais é distinta em relação aos indivíduos de outrora, isso pois, o que era importante para esses últimos, não têm o mesmo valor para os primeiros.

Bauman (2009) faz uma comparação entre as gerações e cita que se a anterior tivesse que pintar um quadro, seria mais meticulosa, teria um maior cuidado ao escolher os solventes e faria de uma forma que se manteria o frescor das cores pela eternidade. Já a geração atual buscaria formas de se imitar os artistas mais celebrados; artistas esses que ninguém sabe quais caminhos seguiram e que vivem à mercê do destino, e não há nada que se possa afirmar, pois tudo pode acontecer. As instalações são frágeis por se saber que não irão sobreviver para o fim da exposição, e dessa forma, logo surgirão outros para realizar uma nova apresentação. Portanto, o autor cita que os jovens não são como obras de artes, são como papéis de parede; logo, precisam ser constantemente atualizados.

O filósofo ainda explica o fato de como um estilo de vida atualmente recomendado pelo mercado, comanda o impulso de se consumir e se comportar, e este mesmo estilo vem não apenas de porta voz, sendo ele pago ou voluntário, mas também de pessoas públicas. Esse estilo de vida também pode ser percebido até mesmo como uma forma de liberdade pessoal, mas quando a pessoa opta por buscar uma outra forma de identidade, ela é rejeitada ou recusada, e, a partir daí, irá perceber o quão curta é essa liberdade. As pessoas que comandam tais estilos acabam ganhando um status de poder, e o autor compara com administradores de uma pista de corrida, onde eles vigiam as entradas, e trabalham paralelamente estimulando os participantes a correrem sempre mais. Ademais, ele destaca que somente aqueles que decidem ser insubordinados, sabem quão severa é a punição. Sua percepção é de que a sociedade foi organizada como sendo uma comunidade de consumidores. Para isso, foi criada

RC: 105379

Disponível em: https://www.nucleodoconhecimento.com.br/psicologia/comportamento-deconsumo 
uma maneira de gerar uma condição indissociável do cidadão contemporâneo. Para viver em sociedade e não ser excluído da hierarquia social, é preciso consumir.

Ainda conforme o filósofo, tudo é feito a partir da manipulação e condução das empresas e profissionais especializados no universo de comportamento e consumo, que inserem nos indivíduos o entendimento de segurança pessoal e pertencimento social quando participam de um determinado grupo de consumo. Igualmente, fazem uso de certos produtos que referenciam um estilo de vida, funcionando como um totem social. Bauman (2008b) evoca Douglas (DOUGLAS e ISHERWOOD, 2009) para explicar que o sujeito no fundo teria medo da rejeição e exclusão social, e, por isso, promoveriam todo o comportamento de consumo material ou imaterial.

Isso ocorreria, conforme Douglas e Isherwood (2009; apud ABREU, 2013), pois sociedades seriam construídas pela economia da dádiva, um ciclo contínuo de dar, receber e retribuir. É uma referência às bases do consumo que serve tanto à sociedade industrial, como às sociedades tribais. Ela define que as dádivas mantêm um padrão particular de relações sociais, e é esse padrão de relações que cria a demanda e os materiais para atender um ciclo, em que se consome para dividir e partilhar - e no caso da internet, literalmente compartilhar, alimentando o sistema de troca e recompensa, e quem rompe com isso, automaticamente está fora. Logo, o fator do medo é reforçado por outros autores, inclusive pelo próprio Bauman (2008a) em outras obras que levantam o mesmo ponto sobre a temática. Seu entendimento é de que o medo humano é um subproduto modificado do medo primitivo animal, servindo de capacidade de autopropulsão e que conduz ao silenciamento, e que isto será abordado novamente mais adiante.

Toda essa questão a respeito da manipulação foi amplamente analisada nas observações da influencer G.P. e seus seguidores, pois ela vendia absolutamente tudo no seu contexto de vida, desde a forma de meditar e se exercitar, até o azulejo

RC: 105379

Disponível em: https://www.nucleodoconhecimento.com.br/psicologia/comportamento-deconsumo 
de seu banheiro. Tudo validado pelos seguidores que enaltecem cada vídeo, e perguntavam onde ou como adquirir tais objetos ou estados de espírito. Em paralelo, os patrocinadores estabelecem o financiamento desse mercado para que seus produtos sejam anunciados despretensiosamente como parte da rotina da influenciadora.

Esse marketing também foi apontado por Bauman (2008b) e foi possível observar nas influencers analisadas. A mensagem de renovação constante e com demarcação efetiva de tempo de troca é feita de forma sazonal através de lançamento dos produtos pelas marcas, e até da obsolescência programada inserida em objetos eletrônicos. Abreu (2013) também discorre sobre esse aspecto, pois tudo é muito rápido, com mudanças criadas para que ocorram intervalos de poucos meses entre um lançamento e outro, e cabe aqui a explicação que esses poucos meses se referem ao tempo cronológico entre três meses e um ano, dependendo do que se fale para mudar. Ela explica que, por exemplo, no mundo da moda têxtil, a cada quatro meses tudo é renovado para gerar novas tendências, enquanto no âmbito tecnológico de celulares, essa média também vem sendo a mesma com modelos que apresentam pequenas alterações de cores ou ícones para um aparelho da mesma empresa. Logo, Bauman (2008b) cita que a lentidão nas relações humanas é compreendida na contemporaneidade como um processo de morte social, o que reforçaria a compreensão aos indivíduos de que não acompanhar tudo isso, é estar desatualizado e antiquado, fazendo com que eles possam se perceber excluídos.

Todos os objetos e coisas que consigam ser inseridos como estilo de vida, são propositadamente colocados de tal forma ao sujeito social, que ele acredita, de uma forma geral, fazer as escolhas por si mesmo, mas sem ser; até porque, essa condução é feita desde tenra idade. Assim, nas redes sociais quem dá continuidade para a lógica de consumo atual são os influencers. Bauman (2008b) entende que para se tornar membro autêntico da sociedade e assim ascender de posição social, é preciso elevar

RC: 105379

Disponível em: https://www.nucleodoconhecimento.com.br/psicologia/comportamento-deconsumo 
o status de consumidor tornando-se mercadoria. Exatamente por isso, estes sujeitos são disputados por marcas para utilizarem seus produtos, e, desse modo, servir como vitrine, tornando esses formadores de opinião do meio digital nos próprios artigos para negócios.

Com as redes sociais e as influencers, os novos hábitos de consumo estão sendo alocados para a internet. Como Bauman (2008b) indica, antes do crescimento de plataformas como Facebook e Instagram, os shoppings centers eram o ponto de encontro entre consumidores e produtos. Atualmente, as mídias sociais permitiram que as mercadorias sejam exibidas por meio de influencers. Assim, perfis como o da influencer L.S., G.P. e outras, misturam estilo de vida e consumo. Isso aumenta o valor de mercado dos produtos por agora possuírem um status de lifestyle.

Usando ainda como exemplo L.S., ela é uma influencer que mantém uma lógica de consumo que está muito ligada com a autoestima e a posição social. Conforme foi conquistando novos seguidores, ganhou visibilidade até de marcas de consumo de alimentos e venda de eletrodomésticos. Seu status no Instagram subiu de mero perfil de consumidora para um perfil que influencia outros consumidores. Isso fez com que ela começasse a fazer propagandas pagas.

A autoestima de seus seguidores entra em jogo no momento que são persuadidos a comprar o que L.S. divulga, e, por sua vez, eles conseguem se aproximar de seu estilo de vida. Não somente as influencers, mas a internet tornou-se solo fértil para que os usuários se convertam eles mesmos em objetos de consumo, em mercadorias, e é justamente o que Bauman (2018b) afirma. Ademais, o autor reforça que a atividade de consumo é solitária e não possui vínculos duradouros. Essa fragilidade é comum nas redes sociais onde uma figura pode ser facilmente esquecida. Logo, as influencers que fazem parte dessa característica servem como vitrine para essa capacidade de persuadir o consumo de produtos e patrocinadores.

RC: 105379

Disponível em: https://www.nucleodoconhecimento.com.br/psicologia/comportamento-deconsumo 
Como explicado anteriormente, no emaranhado de informações que a equipe deste artigo coletou, surgiram alguns grupos que analisamos com atenção e categorizamos para compreensão das partes e depois do todo, e aquela que identificamos como estilo de vida se encaixa perfeitamente com essa explanação de Bauman (2008b; 2009), já que abrange temas usados como conteúdo referentes a autoimagem e intimidade das influencers, como sua vida pessoal, sua rotina, seu estilo de vida e humor.

Quando o influenciador expõe sua vida ao público que o assiste, ele traz à tona a comparação, despertando nos outros desejos por aquilo que não se tem e estimulando a criação de novos objetivos. Como por exemplo, a influenciadora E. ao divulgar um vídeo sobre "como é ter um namoro saudável", além de ditar o padrão que deve ser considerado saudável, criou em seus seguidores a angústia e o desejo de ter um relacionamento como o dela e visto como ideal.

A figura do criador de conteúdo virtual se posiciona dessa forma, adquirindo coisas que muitos de seus seguidores não têm a chance de ter, aparentando estar vivendo o ideal da felicidade. Enquanto isso, do outro lado, o público que consome seu conteúdo está privado de viver essa vida idealizada. Para Bauman (2009), a privação significa infelicidade, afeta a autoestima dos sujeitos e o reconhecimento social. Portanto, para que o indivíduo se sinta privado, é necessário existir um padrão ideal. Logo, na atualidade os influenciadores são os responsáveis por ditar esse padrão.

O autor questiona sobre o que haveria de errado com a felicidade, e argumenta analisando os estadunidenses e não apenas eles, onde em suas buscas pela felicidade, estão ficando cada vez mais ricos, mas não mais felizes. No entanto, os esforços dos estadunidenses, e não somente deles -, em tentar consumir cada vez mais para tentar se satisfazer, causam uma frustração quando ao adquirir o produto ou serviço, aquele vazio não some, fazendo-os consumir ainda mais, em uma procura

RC: 105379

Disponível em: https://www.nucleodoconhecimento.com.br/psicologia/comportamento-deconsumo 
cíclica sem fim. Traçando um paralelo com o fenômeno deste artigo, os influencers são os vendedores desses produtos e/ou serviços milagrosos que prometem (explicitamente ou não) aos seus seguidores, aproximar-se do ideal, do que é certo e da felicidade.

Quando nos questionamos no início das observações, por qual razão milhões de pessoas são seguidores dessas mulheres ou de tantas outras e outros influenciadores digitais? adentramos em reflexões que nunca chegariam em uma conclusão totalmente verdadeira sem a investigação da motivação de cada seguidor individualmente, suas influências socioculturais-históricas, seus sonhos. Porém, algo em comum e mais amplo pode unir esses indivíduos. Poder-se-ia pensar em uma hipótese generalista, que eles sejam movidos por essa busca, tão própria e eterna da humanidade pela felicidade. Por isso que tantas pessoas seguem, curtem, comentam, e compartilham vídeos dessas outras pessoas.

Hoje, nesta sociedade líquida-moderna a qual Bauman (2008b; 2009) se refere, o consumo não está apenas em produtos, mas também em ideias, perfis e estilos de vida. Ao ponto de que a vida de uma pessoa específica, como a influenciadora digital, pode suscitar curiosidade, idealização e inspiração em milhões de pessoas. As influenciadoras podem ser vistas como algo mais próximo da felicidade e pela qual seus seguidores, consumidores líquido-modernos, buscam. Por isso suas roupas, posicionamentos, alimentação e até mesmo o cotidiano se tornam caminhos a serem observados, admirados e muitas vezes, copiados.

Bauman (2009) diz que a energia do desejo da felicidade pode ser dividida em dois tipos de forças: centrípeta (de fora para o centro) ou centrífuga (do centro para fora). Assim, para o autor, a busca da felicidade pode ser resumida na preocupação com o próprio bem-estar do indivíduo, ou, diante de sua preocupação com o bem-estar do outro. As duas alternativas, porém, não são necessariamente contraditórias - podem

RC: 105379

Disponível em: https://www.nucleodoconhecimento.com.br/psicologia/comportamento-deconsumo 
trabalhar juntas com nenhum ou quase nenhum conflito. No entanto, se há uma relação correlacionada, é a da força centrífuga para com a força centrípeta, onde ser bom com o outro reforça o sentimento de estar bem consigo.

Assim, foi observado pela equipe deste artigo que constantemente a figura do influenciador digital dita não somente um produto ou serviço a ser adquirido, mas também comportamentos que devem ou não ser mantidos para seus seguidores serem felizes. Essa questão está presente nas pautas femininas e padrões estéticos, como, por exemplo, cortar ou não o cabelo, manter uma depilação constante ou reduzi-la, dentre outros assuntos. Dessa maneira é possível que algo que nunca incomodou uma pessoa, após assistir um vídeo no Youtube ou ver uma postagem no Instagram, passe a incomodá-la.

Nas redes sociais, o Eu e o estilo de vida se tornam o centro, o produto e o produtor de entretenimento, idealização e projeção para os consumidores. Descrever, capturar e filmar suas rotinas; como a que horas acordam, almoçam, o que comem, bebem, o que vestem, quais são as marcas, quais são os preços, onde vão, no que acreditam, religiões, com quem namoram, com quem moram, brigas, conflitos, conquistas, alegrias... Tudo o que se passa na vida de uma influencer, é divulgado, visualizado, compartilhado, comentado, como se os seguidores assistissem a um filme ou novela e pudesse acompanhar o personagem o tempo todo. Um processo narcísico aberto, e às vezes, sem restrições por parte das influencers. E por consequência, os seguidores querem repetir esse comportamento de exposição contínua e exacerbada.

Christopher Lasch é citado por Bauman (2009) como especialista no comportamento desses novos narcisistas. Seriam pessoas que ao serem confrontadas com suas angústias internas, revertem isso em comportamento de sedução para obtenção de atenção e aplausos, e que no caso específico dos influencers, o mecanismo fica condicionado aos likes e comentários enaltecidos dos seguidores. Esse processo

RC: 105379

Disponível em: https://www.nucleodoconhecimento.com.br/psicologia/comportamento-deconsumo 
seria imprescindível para o narcisista sustentar seu self extremamente inseguro, segundo o autor. É interessante perceber como esse conceito se encaixa com essa nova profissão de influencers e que segue em crescimento constante. Alguém que decide simplesmente compartilhar fragmentos editados de seu dia a dia e receber por isso interações diárias com indivíduos de diferentes lugares do mundo que possam acompanhar, identificar-se e almejar aquele determinado estilo de vida que está sendo vendido como ideal.

Freud (1972; 2011), Lacan (SAFATLE, 2007) e Zimerman (2004) afirmam que dentro de um certo grau, a humanidade é narcisista, mas certos indivíduos ultrapassam os níveis de normalidade, adentrando assim, o narcisismo clínico (ou seja, patológico). Nesses casos, Zimerman explica que este indivíduo carrega uma baixíssima autoestima, por vergonhas, fracassos e humilhações, e tenta ocultar isso socialmente através da apresentação primordial de status econômico e/ou social, assim como, passa a ter sua vida em negação de realidade e em constante atitude defensiva.

Tem-se aí, um sujeito possessivo, prepotente, egoísta, autoritário, com intolerância às frustrações e críticas, e comumente apresenta repulsa por envelhecimento, doença ou morte. Ademais, além de carregar uma inveja destrutiva (inclusive velada) e a oposição à hierarquia (pois ele deve ser o centro das atenções e comando), o narcisista provoca situações para conquistar súditos e enaltecer suas próprias qualidades (muitas vezes inexistentes e criadas utopicamente como mecanismo de defesa). Mas em contrapartida, deprecia, ataca e menospreza (física, intelectual e/ou profissionalmente) todos aqueles que não sejam considerados semelhantes (ou gerem o sentimento de ameaça). Cabe observar que o narcisista desqualifica de fato todos aqueles que de alguma forma sejam efetivamente considerados mais do que ele, e, portanto, há uma necessidade de apresentar-se sempre no topo da pirâmide.

RC: 105379

Disponível em: https://www.nucleodoconhecimento.com.br/psicologia/comportamento-deconsumo 
A equipe observou uma constância de relatos das vidas pessoais dessas influencers, assim como, seus estilos de vidas e rotinas. Os relatos sobre suas vidas pessoais aparecem junto com narrativas de vivências que estão relacionadas a temas que provocam maior repercussão e engajamento nas redes sociais, como cortar o cabelo bem curto, e a relação intrínseca do cabelo com a aparência, beleza e feminilidade da mulher.

Nesses cotidianos, os dias eram apresentados sempre como corridos, mas os estilos de vida são dicotomicamente sugeridos como positivos e otimistas, não levando em consideração os privilégios que algumas pessoas possuem e que facilitam determinadas rotinas e hábitos percebidos socialmente como mais saudáveis, leves e felizes:

No meio do vídeo, aparece do nada ela sendo filmada (possivelmente pelo marido) fazendo exercícios de yoga. Quem filma faz questão de mostrar "G.P." todo o tempo, mas movimentando-se de tal forma que revele todo o ambiente extremamente amplo da sala dupla da residência do casal. (Notas de equipe, 2020)

O uso do humor foi também uma estratégia utilizada por uma das influenciadoras observadas para contar sobre sua rotina de modo mais dinâmico e atrativo aos seus seguidores:

No dia 24/09/2020, "P.Q." apareceu pela primeira vez em um vídeo com a legenda: "eu, cara de pau, entrando na farmácia do shopping só para me pesar". Vestindo uma camiseta laranja e utilizando suas muletas, ela aparece dentro de uma farmácia, sorrindo e acenando para a câmera, enquanto caminha até uma balança. Os comentários de seus seguidores são de pessoas contando o que fazem quando estão nessa situação e de funcionários de farmácias relatando sobre clientes que têm atitudes parecidas. (Notas de equipe, 2020)

A venda da autoimagem repleta de felicidade, tempo, e, às vezes, dinheiro, cria uma sentença muito peculiar. Cada influenciadora articula de forma diferenciada, mas chamando atenção para si sob um determinado e poderoso aspecto. Alain Ehrenberg

RC: 105379

Disponível em: https://www.nucleodoconhecimento.com.br/psicologia/comportamento-de$\underline{\text { consumo }}$ 
(apud BAUMAN, 2008b, p. 121-122) explana que "os sofrimentos humanos mais comuns nos dias de hoje tendem a se desenvolver a partir de um excesso de possibilidades, e não de uma profusão de proibições, como ocorria no passado". De acordo com esse autor, expressões como ter tempo, faltar tempo e ganhar tempo, são absorvidas pela sociedade provocando desgaste e ansiedade, sobretudo se o sujeito for incapaz de atingir o propósito. Bauman (2008b) completa afirmando que isso se estabeleceria como um complexo de inadequação que reflete toda essa aflição da vida líquido-moderna. Assim, o fracasso também estaria ligado intrinsecamente a não ter tempo, e não apenas a não ter dinheiro.

Essa afirmação leva diretamente a G.P., que vendia aos seus seguidores a união dessas duas potentes vertentes. Ela apresentava um estilo de vida de alto status inclusive mostrando, por exemplo, festas caras e viagens internacionais paradisíacas -, e um vasto cardápio de tempo para fazer absolutamente tudo o que desejava, mas que um adulto proletariado comum e assalariado, que trabalhe e/ou estude, e por mais organizado que seja, não conseguiria em termos reais fazer tantas coisas e sorrindo todos os dias do ano. Ela efetivamente vendia a percepção de que era muitíssimo feliz porque efetuava tudo aquilo. Aliás, igualmente afirmava que era muito abençoada, fazendo questão de repetir isso todo o tempo ao apresentar suas conquistas ou objetos (caros) que foram comprados ou presenteados, mas que supostamente seriam dádivas de Deus como premiação por pronunciar a palavra gratidão a todo momento, e, evidentemente, banalizando o termo. Em paralelo, colocava-se em competição com outras pessoas, pois cada vez ela tinha mais posses e conquistas e por isso, era muito mais feliz. Se alguém desejasse ser igual, necessitaria imitá-la, mas, mesmo assim, não conseguiria alcançá-la. Assim, a influencer mantinha o sentimento de inadequação de seus seguidores, caso eles não conseguissem fazer nenhuma das coisas que ela propunha. Ao mesmo tempo, ela podia renovar seu constante prazer e sentimento de viver intensamente. É esta manutenção do processo

RC: 105379

Disponível em: https://www.nucleodoconhecimento.com.br/psicologia/comportamento-deconsumo 
de satisfação que cria constantes necessidades num ciclo interminável de consumo, e com o demarcador de que os sujeitos não serão nada sem aquilo.

Bauman (2018b) aponta uma gravidade sem precedentes nessa engrenagem quase perpétua, pois as insatisfações diante do que é anterior tornar-se-iam tão altas, que isso justificaria, por exemplo, os inúmeros casos de cirurgias plásticas em indivíduos que destroem sua autoimagem diante da frustração de nunca ficarem suficientemente satisfeitos com a intervenção anterior. Torna-se uma busca incessante por um vazio que nunca é preenchido, e isso ocorre em todos os âmbitos, não somente com as cirurgias. Esse comportamento descabido vem sendo vastamente incentivado pelos influenciadores digitais, e que apresentam dicas de beleza e saúde (sem embasamento), como G.P. fazia a cada vídeo.

É interessante a análise por esse ponto de vista, pois pôde-se comparar as influencers G.L. e G.P. Essa segunda caracterizou-se como a influenciadora digital do sexo feminino com mais seguidores no Brasil, mesmo falando e conduzindo seus apreciadores às práticas absurdas que ela indicava, com risco direto à danos de saúde mental e física. Ademais, com apresentações extremamente fúteis e imaturas, G.P. passava todo o tempo exibindo a imagem de uma pessoa feliz e abençoada (como já citado), tendo tudo o que desejava na vida e por um único motivo: ela agradecia muito a Deus todos os dias.

Observe que enquanto G.L. (a influencer transexual) recebia ofensas e ameaças, diretas ou indiretas, apenas pelo fato de ser uma mulher transgênero - e com um conteúdo pautado em equilíbrio e aconselhamento constante de acompanhamento médico e psicológico aos seguidores -, G.P. era enaltecida como uma pessoa

RC: 105379

Disponível em: https://www.nucleodoconhecimento.com.br/psicologia/comportamento-deconsumo 
maravilhosa, mesmo propondo para as pessoas receitas para curar depressão como esta:

Você acordou meio pra baixo? Tira isso da cabeça! Se espreguiça, agradece, sai de casa, vai fazer coisas que você gosta com suas amigas, amigos, tá bom?! Todo dia que vocês acordarem, vocês têm que falar, "A regra do dia: 'ser feliz e ser uma pessoa melhor". Gente, vocês têm ideia do quão a vida passa rápido? (01:03 / 01:17. Trecho de transcrição de vídeo). (Notas de equipe, 2020)

A partir desse comportamento, seus seguidores abraçavam os discursos seguintes para o suposto alcance do equilíbrio espiritual e físico, mesmo ela apresentando a dicotomia da ostentação da riqueza paralela. Concomitantemente, a influencer G.P. mostrava aos seguidores que possuía haters, que - segundo ela - a perseguiam e atacavam sem motivos, afinal, ela era uma pessoa grandemente abençoada. Redigindo este exato parágrafo neste artigo, o leitor talvez possa entender que seja apenas um exagero de redação, mas não; eram palavras da própria influencer em vários vídeos. Isso foi evidente todo o tempo, e muito mais do que qualquer outra das influenciadoras observadas, o que denota uma inversão de discurso extremamente manipuladora.

Essa inversão de discurso é explicada por Chaui $(2011 ; 2012 ; 2017)$ como ideológica. A ideologia funciona como ocultamento de relações sociais, deixando algo em plano velado, além de que, é uma inversão da realidade. Toma-se a ideia e inverte-se a realidade a partir da própria ideia para culpar o outro e ocultar relações, essa inversão de discurso provém das classes dominantes que criam estereótipos com o intuito de ocultar os elos de dominação e exploração. Assim, o indivíduo retira o valor do outro e traz para si a legitimação da ideia de outros como sendo sua, e, além disso, com todo o tipo de distorção. G.P. fazia isso o tempo todo, e ainda agregando uma conduta narcísica.

RC: 105379

Disponível em: https://www.nucleodoconhecimento.com.br/psicologia/comportamento-deconsumo 
Entendendo todo esse processo narcísico, e comparando com o que a equipe pôde ver em G.P. e até na influencer T., que vende a imagem de forte mulher e mãe, mas mantém o controle dos seguidores usando os filhos pequenos, como mãe sofredora e alimentando o discurso de ódio aos homens, e expondo um sobrinho doente. No caso de T., a autopromoção usando terceiros é muito palpável, e novamente, tanto ela quanto G.P. conduzem ao universo do discurso ideológico.

Fatidicamente, tudo vai se entremeando e compondo o que a equipe deste artigo entende como a categoria questões sociais atuais, que reforça toda essa temática anterior de padrão estético e de beleza atual, do machismo na sociedade, e, o processo de desconstrução social e cultural. Descrevendo mais precisamente, podese até incluir os discursos de ódio cada vez mais perceptíveis e gritantes que saem do universo virtual e alcançam o físico.

Cabe aqui iniciar a análise sobre a temática dos haters já citados anteriormente. Eles são pessoas que acompanham as postagens do(a) influenciador(a) não por admirálo(a), mas sim, esperando qualquer falha para apontar e incentivar o discurso de ódio.

Ao pregarem uma vida perfeita, é deixado de lado o ser humano por completo, que como tal, comete erros e acertos, e o influencerpode tornar-se mais suscetível a essas ações. Portanto, na internet não existe espaço para o sujeito errar, pois se isso ocorrer, o cancelamento está pronto para ser efetuado. Neste ponto, pode-se retornar a temática dos medos que compreendem a temática do cancelamento, e citados de forma breve anteriormente. Certos temores reais e perceptíveis seriam silenciados através das inversões ideológicas, como a concepção do "fracassado ou vitorioso, por exemplo. Essa normatização de muitos medos fictícios e descrédito de outros reais, seriam um dispositivo criado socialmente para tornar o medo em algo tolerável e até reprimível diante do perigo iminente.

RC: 105379

Disponível em: https://www.nucleodoconhecimento.com.br/psicologia/comportamento-de$\underline{\text { consumo }}$ 
Por sua vez, Baum (2019) corrobora que o medo é transmitido e faz parte de uma evolução cultural passada de indivíduo a indivíduo. Isso gera pessoas com poder e surge o lugar de dominador que controla outros indivíduos, e por isso se torna tão fácil o comando do cancelamento oriundo diretamente do influencer. Ele dita aquilo que pode estar errado, criando o sentimento de raiva em seus seguidores, e, paralelamente, de temor pela própria integridade. Observe que é bem diferente de indivíduos sociais que chegam à conclusão por si mesmos, de findar a relação de negócios ou admiração a alguém, diante da descoberta daquela pessoa fazer parte de algum tipo de escândalo que possa gerar danos à terceiros, e isto vem se efetivando bastante recentemente como movimento de grupo social. Isto é reforçado por Byung-Chul (2018), que apresenta dois trechos sucintos que explanam bem o fenômeno do cancelamento. No primeiro trecho, o autor fala como funciona o poder do discurso em forma de comunicação:

O poder como meio de comunicação consiste em, tendo em vista a possibilidade do Não, aumentar a probabilidade do Sim. O Não é sempre alto. A comunicação de poder reduz consideravelmente o ruído e o barulho, ou seja, a entropia comunicativa. Assim, a palavra de poder elimina repentinamente o barulho que se infla. Ele produz um silêncio, a saber, o espaço para ações. (BYUNG-CHUL, 2018, p. 11)

Em outro trecho, ele fala da sociedade da indignação, que é praticamente a cultura do cancelamento, e o quanto isso acaba sendo efêmero.

As ondas de indignação são eficientes em mobilizar e compactar a atenção. Por causa de sua fluidez e volatilidade elas não são, porém, apropriadas para organizar o discurso público, a esfera pública. Elas são incontroláveis, incalculáveis, inconstantes, efêmeras e amorfas demais para tanto. Elas se inflam repentinamente e se desfazem de maneira igualmente rápida. (BYUNG-CHUL, 2018, p. 15)

Isto é análogo ao medo diante da maldade ao qual uma pessoa possa ser alvo. Bauman (2008a) classifica como mal, a incapacidade de se decifrar ou explicar regras quebradas socialmente. Ele explica que esse pensamento é de origem ancestral nas

RC: 105379

Disponível em: https://www.nucleodoconhecimento.com.br/psicologia/comportamento-deconsumo 
religiões e pautada na punição a quem descumpriu tais condutas, sendo castigada por suas ações pecaminosas. Ou seja, as pessoas que estivessem fora do padrão social perfeito e até comumente que estivessem ofendendo a Deus de alguma maneira, poderiam sofrer ataques haters extremamente ofensivos. Esses haters, orientados pela figura de poder do influencer, entendem que receberam autorização para atacar aqueles que ameaçassem a imagem ou integridade dessa persona idealizada.

Por mais que a profissão de influenciador(a) digital seja nova, ela já tem gerado consequências negativas para muitos desses sujeitos, exceto economicamente, e para as pessoas que consomem seus conteúdos. A constante busca por legitimação, por mais sucesso, por um maior número de seguidores, pela carga de reproduzir e afirmar o padrão de beleza ou de criticá-lo, constantemente são apenas algumas das problemáticas enfrentadas por um criador de conteúdo. As plataformas cobram constância de seus influenciadores; é preciso postar todos os dias e diversificar as ferramentas se quiser que seu perfil tenha alcance. Mas, muitos criadores têm expressado seu descontentamento com as exigências dos algoritmos.

Realmente quando se fala de internet e redes sociais tudo parece passageiro e extremo, pois o sujeito gosta de uma publicação e dá um like, ou não gosta e dá um deslike; ou gosta de um influenciador ou é hater; então, aparentemente não existe meio termo. Essa condução de comportamento apresenta inclusive pessoas que atacam até outros influencers com pautas ativistas, como foi o caso da transfeminista (assim ela se autointitula), G.L. Para continuar sendo relevante virtualmente, uma influenciadora precisa estar dentro do que é esperado pelo seu público-alvo. Hoje, o que algumas pessoas querem ouvir, discutir e compartilhar, são informações sobre causas e problemas sociais, mas claro, isto não é uma regra. É importante ressaltar que para todos esses envolvidos, o que importa é falar sobre os assuntos, e não

RC: 105379

Disponível em: https://www.nucleodoconhecimento.com.br/psicologia/comportamento-deconsumo 
necessariamente ter um posicionamento correto ou verdadeiro, e este é o grande problema que muitos desses influencers propagam.

As influencers em alguns dos vídeos analisados pelo grupo deste artigo, falam sobre como emagrecer, assim como, suas rotinas de cuidado da pele, cabelo e do corpo. As dicas e informações são dadas em forma de conselhos" ou de vivências pessoais de cada uma, mesmo sem nenhuma influenciadora ter divulgado em suas redes sociais, formações acadêmicas nas áreas de saúde (mental, física e/ou estética). Outra influenciadora, fala justamente em como é difícil atingir esses padrões de beleza e estética e como isso pode influenciar outras mulheres a não se aceitarem como são.

O machismo é outro tema constante nas produções das influenciadoras, seja exemplificando situações vivenciadas por essas mulheres em seus próprios relacionamentos, ou falando sobre como reconhecer essas atitudes machistas na sociedade.

Outro tema explorado pelas influencers é a desconstrução pessoal. Isso está ligado ao reconhecimento de machismo, racismo, LGBTfobia, gordofobia, entre outros preconceitos e estereótipos enraizados na sociedade e nos processos de desconstrução dos comportamentos e posicionamentos individuais e sociais no dia a dia. Nos vídeos e postagens, é ressaltado que a desconstrução é um processo, e por isso precisa o tempo todo ser revisitado e ter um olhar atento sobre ele. Além disso, pode levar anos até perceber e se desprender de um estereótipo ou preconceito.

$\mathrm{Na}$ atualidade, falar nas redes sociais sobre grandes pautas e alguns comportamentos, acaba tomando uma dimensão que adentra as questões sociais, e que ganharam nas últimas décadas atenção dos consumidores de conteúdo, produtos e serviços. Aqui, pode-se trazer Bourdieu (2007), já que este autor pondera que, de uma forma geral, o advento do consumismo gerou o reforçamento de padronização social e excluindo todos aqueles que não seguem esses modelos que outrora eram RC: 105379

Disponível em: https://www.nucleodoconhecimento.com.br/psicologia/comportamento-deconsumo 
coercitivos, mas agora são apresentados como escolhas. Bauman (2008b) acrescenta que a novidade diante do efêmero sobrepujou o valor da permanência, o que se reflete diretamente nas relações humanas do novo milênio. A necessidade de ter tudo nas mãos e de forma frenética, precipita o descarte do objeto inanimado mais rápido ainda e é transferido ao fator humano, gerando o afastamento do outro como um igual lixo descartável, ou seja, a exclusão do outro torna-se muito fácil.

Esse imediatismo é mostrado na impaciência das pessoas diante da mínima falha do outro indivíduo, por menor que seja, esquecendo-se de todos os outros valores positivos que essa pessoa possa ter. Nesse ponto, o autor relaciona isso com a busca pela felicidade, já que se o sujeito tem tudo o que quer, não consegue ser feliz, então, isso seria visto socialmente como a culpa sendo inteiramente dele. Portanto, ser emancipado para ter, falar e fazer tudo o que se quer, estaria no patamar da ostentação de mostrar que é feliz, e sem isso, o sujeito seria um total derrotado. Conforme Bauman (2008b), daí viria a necessidade de o indivíduo mostrar a todo tempo que tem objetos (ou status) e que é feliz, mesmo sem ser ou ter. A perda de qualquer um desses fatores o conduz à derrocada da autoestima diante da percepção de humilhação social.

Nicole Aubert (apud BAUMAN, 2008b, p. 120-121) sugere que as sociedades atuais se encontram em estado de emergência. Isto é revelado na constante manutenção de sentimento intenso de urgência por meio da necessidade social de ter algo, e, assim, cria-se um fluxo contínuo de alerta e ansiedade, e modificando-se como ilusório ao ter esses sentimentos dissipados e entendidos como alívio quando o sujeito consegue consumir. Esse processo produz um outro efeito: os indivíduos tornam-se intolerantes e frustrados quando não conseguem ser satisfeitos imediatamente ou no tempo esperado.

RC: 105379

Disponível em: https://www.nucleodoconhecimento.com.br/psicologia/comportamento-de$\underline{\text { consumo }}$ 
Bauman (2008b) faz igualmente menção à perda da identidade original de cada um, e que se já não fosse o bastante diante da padronização visual e comportamental, as sociedades estão sendo igualmente conduzidas a ignorarem as relações de contato face a face. Isso vem sendo intensificado através dos processos tecnológicos de tudo aquilo que nos rodeia, já que muitas das ações individuais, como fazer compras ou resolver problemas no banco, podem ser feitas de forma autônoma e sem o auxílio de outra pessoa. Assim, os sujeitos seguem e dão mais importância àquilo que se apresenta como um modelo de futuro, pois de novo, o passado não interessa. $O$ autor evoca Elzbieta Tarkowska (apud BAUMAN, 2018b), que desenvolveu o conceito de seres humanos sincrônicos, vivendo apenas do presente, inconsequentes e sem necessidade de vínculos com outros. Portanto, as relações humanas desses indivíduos tornam-se todas frágeis, superficiais e solitárias no âmbito presencial.

No percurso das análises, a categoria que a equipe deste artigo classificou como consumo contém os temas de propagandas e publicidades durante os vídeos e postagens das influencers. Contudo, conforme os parágrafos anteriores demonstraram, a questão da sociedade consumista vai muito além do que a aquisição do objeto material. Hoje, as redes sociais são usadas não apenas para as interações, mas também para esse consumo generalizado.

Efetivamente, anúncios e propagandas são percebidos em grandes quantidades no Facebook, Instagram, Youtube e outras plataformas. Esse incentivo ao consumismo pode ocorrer de maneira direta como um anúncio de cinco segundos que aparece antes do vídeo dos influencers e não pode ser pulado. No entanto, a técnica mais utilizada entre as empresas é se apoiar na imagem e no poder de comunicação de influenciadores digitais. Logo, o comportamento mais observado foi de incentivo ao consumo através das publicidades para marcas e serviços, sendo isso de forma direta ou indireta no conteúdo das influenciadoras. Assim, existe a percepção de que quem consome $\mathrm{o}$ que as redes sociais propagam, cresce em níveis hierárquicos na

RC: 105379

Disponível em: https://www.nucleodoconhecimento.com.br/psicologia/comportamento-deconsumo 
sociedade. Logo, Bauman (2008b) considera que o principal fator de estratificação atual é o consumo, e este é o responsável por orientar a distribuição de consideração e exclusão social. Dessa forma, o público é chamado a dar voz àqueles que possuem um poder de consumo alto, muitas vezes por querer se identificar e consumir assim como aquela figura de autoridade.

A influencer L.S. (conhecida como P.Q.) costuma ser discreta com relação aos seus hábitos de consumo, mas eles são temas frequentes em suas postagens na rede social Instagram. Um vídeo postado no dia 26 de setembro de 2020 mostra a influencer indicando qual tipo de consumo prefere. Ao invés de comprar uma blusa, ela indica que prefere gastar com hábitos alimentares. Ainda que seja essencial para a sobrevivência humana, a alimentação também se tornou uma maneira de consumir e propagar um estilo de vida. Quando L.S. mostra de qual maneira gasta seu dinheiro, influencia seus espectadores para consumirem da mesma maneira e integrar em seus hábitos alimentares os mesmos tipos de refeição.

L.S., como outras influencers observadas - incluindo potencialmente a influencer G.P. -, vai de encontro com o pensamento Bauman (2008b) quando promove e encoraja um estilo de vida consumista. Sua estratégia de posicionamento segue uma linha de existência por meio do consumo.

Bauman (2008b) considera que os sujeitos sociais que não estão presos a essa lógica de consumo são excluídos socialmente, por não serem percebidos como indivíduos capazes de manter uma sociedade consumista, e, assim, não são considerados como válidos para governos e indústrias. $\mathrm{O}$ autor também indica que por meio de terapias compulsórias e até mesmo punição, o mercado exige que esses excluídos sejam colocados novamente na lógica de consumo para continuarem alimentando essa engrenagem. Logo, o incentivo ao consumo através das publicidades pode acontecer de modo sutil, usando a imagem e o poder de comunicação das influenciadoras para

RC: 105379

Disponível em: https://www.nucleodoconhecimento.com.br/psicologia/comportamento-deconsumo 
transmitir a mensagem e vender o produto ou serviço que nem sempre está diretamente ligado com o conteúdo produzido por elas. Outro meio da utilização das imagens e do poder de influenciar os seguidores das produtoras de conteúdo digital, são as publicidades diretas.

Uma ferramenta que "P.Q." frequentemente utiliza para alcançar seu público de 1 milhão de seguidores é o Stories presente no Instagram. A primeira postagem no stories do dia 20/09/2020 foi uma propaganda de um restaurante chamado de "XXX". Ela gravou um pequeno vídeo de cinco segundos com os produtos desse estabelecimento e marcou o Instagram da marca. O vídeo, ainda que curto, causa uma sensação de desejo no público que a assiste (e isso foi relatado nos muitos comentários), o que faz com que o restaurante ganhe mais seguidores e clientes. (Notas de equipe, 2020)

Quando a publicidade não é para terceiros, o foco do incentivo ao consumo se volta para as próprias influenciadoras e seus produtos e serviços:

(...) Ao lado direito tem uma outra planta menor e uma espécie de banqueta, alguns exemplares visíveis do livro escrito por "M.", intitulado "XXX". No centro, está "M.", sentada, apoiada em uma espécie de bancada ou mesa branca. (...) Durante todo o vídeo, "M." se autorreferência frequentemente, indicando e citando outros quatro vídeos, mostrando onde eles podem ser acessados, como uma forma de "puxar" o público que está assistindo o vídeo utilizado neste relatório para outros vídeos do mesmo canal. (Notas de equipe, 2020)

Outro ponto muito importante trazido por Bauman (2008b, p. 117) e que se encaixa completando os parágrafos anteriores, está no que ele denomina de guerras de reconhecimento. Ali, configura-se o terreno da legitimação onde oscilaria o princípio da realidade e o princípio do prazer, e o sujeito teria que decidir se estaria pronto para sacrificar seu próprio bem-estar em detrimento do cumprimento das responsabilidades morais aos outros. Contudo, Abreu (2013) reforça que ocorreria uma constante fuga desse processo, pois o entendimento hedonista ficaria muito mais evidenciado pela percepção do eu mereço que é referenciado por Douglas e Isherwood (2009).

RC: 105379

Disponível em: https://www.nucleodoconhecimento.com.br/psicologia/comportamento-deconsumo 
Bauman (2008b) percebe como algo perturbador essa relação de confiança com pessoas desconhecidas na rede virtual. Contudo, o consumidor/usuário sente-se confiante até pelos dispositivos de segurança e possibilidade de corte de comunicação imediata se assim desejar. Mas, isso também faz parte desse novo universo da cultura consumista, já que a pessoa novamente pode descartar rapidamente aquilo que não a agrada, e, outra vez, ela tem a possibilidade de criar e se manter de variadas ilusões.

Desta forma, o autor faz a prospecção de que toda essa condução alienante e de impaciência torne-se permanente. Essa necessidade de aceitação social virtual estaria longe de diminuir ou findar, pois, segundo Francis Jauréguiberry (apud BAUMAN, 2008b), os internautas podem experimentar novos e diferenciados eus e protegidos de decepções e punições atrás da virtualidade. Assim, em sua maioria, os usuários representam personalidades irreais, com vidas irreais, que servem de incentivo aos outros para que sigam esse projeto de existência utópica. Ademais, o sofrimento diante das perdas no presencial torna-se nulo ou muito diminuído, e novamente as relações humanas revertem-se para uma estrutura objetal descartável no universo virtual. Sem riscos.

Observando e analisando todo a material coletado pelo grupo de pesquisa deste artigo, pôde-se acordar com Bauman (2008b) que a socialização virtual no que se refere às interações entre influencers e seus seguidores, é orientada pelo marketing, e, assim, tudo faria parte de uma logística pensada para controle social e com objetivo mercadológico.

O autor ainda agracia com o pensamento final de que a vida não dá remédios para os dilemas e o ser humano não nasce com respostas, pois cada um vive em meio às incertezas e ninguém está livre desta situação, assim como, todos correm o risco de fracassar e se desapontar em algum momento. Bauman (2009) acrescenta que quando se busca uma vida mais digna, satisfatória e mais feliz, é inevitável a fuga pela

RC: 105379

Disponível em: https://www.nucleodoconhecimento.com.br/psicologia/comportamento-de$\underline{\text { consumo }}$ 
incerteza e pelos erros, confiando apenas em um guia, uma estrela que possa levar a este patamar. Todavia, não se pode esquecer que é uma escolha pessoal de cada um, a decisão de permitir ser guiado. Assim, o que a equipe alcançou para encerrar este cruzamento das observações com os estudos de Bauman, é que o fenômeno das redes sociais e internet não tem volta, e faz parte de um movimento social e futurista.

As influencers possuem uma ferramenta incrível que poderia ser utilizada positivamente como meio de educação, ativismo e inspiração para novos pensamentos sociais. Contudo, a manipulação mercadológica para controle da sociedade que busca por uma felicidade montada, unida a uma série de fatores, inclusive medo de exclusão, e justamente por cada sujeito talvez não saber quem ele mesmo é, conduz o usuário/seguidor a fatidicamente manter-se nesse processo ilusório de escolhas que não são as dele, e muitas vezes fúteis, deturpadas e até perigosas. Mas sim, a decisão é totalmente individual, pois todos podem fazer a sua escolha final.

\section{CONSIDERAÇÕES FINAIS}

De uma maneira geral, enquanto estudantes de Psicologia, este artigo privilegiou nossa perspectiva sobre a elaboração dos sofrimentos e comportamentos dos sujeitos na busca de si e do outro especificamente no universo virtual, mas que se materializam nos espaços sociais físicos e cotidianos.

O questionamento norteador inicial: o que leva sujeitos a serem suscetíveis às mudanças de seus comportamentos mediante o comando de alguém desconhecido? Foi respondido já que a equipe entendeu como funciona o mercado de influenciadores digitais, e como essas pessoas conduzem seus seguidores para que permaneçam interligados e aceitem os comandos de alguém desconhecido.

RC: 105379

Disponível em: https://www.nucleodoconhecimento.com.br/psicologia/comportamento-deconsumo 
As influenciadoras digitais de fato impactam no comportamento dos indivíduos que as seguem, e podem alterar os processos de consumo desse público-alvo. Nossas hipóteses também foram confirmadas, e essas influencers são de fato muitas vezes assessoradas por empresas com interesse em investir, projetando uma maior ascensão diante do grande número de seguidores, e que podem visualizar e consumir tais produtos e estilos de vida. Quanto maior a projeção da influenciadora e com mais empresas oferecendo suporte, mais assessoradas por profissionais de marketing elas se tornam, sendo ainda auxiliadas na criação e manutenção de conteúdos que ditam os conceitos do que é felicidade.

Ademais, as influencers efetivamente suscitam a intensa exposição pessoal, tornando-se o principal produto de consumo, gerando assim, o desejo naqueles que as seguem de fazer o mesmo: de serem os próximos targets de sucesso. Logo, surgem outros tantos exacerbados comportamentos de narcisismo por parte da população desconhecida, mas que anseiam a mesma alta exposição e reconhecimento público. Por isso, quando um indivíduo do público-alvo se identifica com uma determinada influencer, e até desejando ser o que ela é ou ter aquilo que ela apresenta como sucesso, esse sujeito vai acatar e consumir o que the é ofertado.

Muitas influenciadoras digitais, seus seguidores e até os haters estariam em simbiose com três pontos principais de fomentação do psiquismo de cada um individualmente e projetada para grupo: o narcisismo, o medo da exclusão e invisibilidade, e a busca por uma felicidade. Por outro lado, foi possível detectar que outras influenciadoras tentam utilizar-se dessa ferramenta que pode ser extraordinária, produzindo informações de acréscimo social de forma útil e positiva. Logo, fica a compreensão de que cada indivíduo age e reage conforme seu entendimento de vida, apoiando-se naquilo que se identifica e até nas próprias escolhas que quase todos são capazes de fazer.

RC: 105379

Disponível em: https://www.nucleodoconhecimento.com.br/psicologia/comportamento-deconsumo 
A equipe acredita que executar todos os processos de coleta e análise de dados deste estudo, revelou algumas relações atuais de como muitas das pessoas comuns se expõem na internet e fazem uso das redes sociais, já que elas se espelham e vislumbram esse lugar de visibilidade dos influencers. A experiência também mostrou o valor de contemplação dos vínculos entre as pessoas, mesmo no virtual. Ao se analisar diferentes influenciadoras com conteúdo diversos, o grupo percebeu que apesar do desejo de ter uma suposta verdade e um conteúdo certo a ser consumido, cada indivíduo tem seus conflitos, desejos e projeções, e que são pessoais de cada um e difíceis de intervir nas redes sociais.

Com isso a equipe compreendeu que o profissional de Psicologia necessita não somente estar atento e sabendo verdadeiramente escutar, mas, perceber e entender aquilo que não é dito. Da mesma maneira, deve estar disposto a ampliar consideravelmente seus conhecimentos, para assim, agregar uma visão mais consistente e desenvolvida sobre o contexto histórico dos indivíduos. Assim, os desafios contemporâneos devem ser constantemente repensados e reavaliados, levando a contínuos questionamentos sobre as mudanças sociocomportamentais que ocorrem cada vez mais rápidas, na velocidade do apertar de um botão.

\section{REFERÊNCIAS}

ABREU, Liliane Alcântara. Relação afeto, memória e cor: implicações da memória afetiva e seu impacto no consumo de cor na decoração. Rio de Janeiro, 2013. Artigo. 23 f. Trabalho de Conclusão de Curso (Especialização em Pesquisa de Comportamento e Consumo) - Faculdade SENAI-CETIQT, Rio de Janeiro, 2013.

BAUM, William M. Compreender o behaviorismo: comportamento, cultura e evolução. Tradução Maria Teresa Araújo Silva [et al.]. 3. ed. Porto Alegre: ARTMED, 2019.

RC: 105379

Disponível em: https://www.nucleodoconhecimento.com.br/psicologia/comportamento-de$\underline{\text { consumo }}$ 
BAUMAN, Zygmunt. A arte da vida. Tradução Carlos Alberto Medeiros. Versão digital. Rio de Janeiro: Zahar, 2009.

Medo Líquido. Tradução Carlos Alberto Medeiros. Rio de Janeiro: Zahar, 2008a.

Vida para consumo: a transformação das pessoas em mercadoria. Tradução Carlos Alberto Medeiros. Rio de Janeiro: Zahar, 2008b.

BOURDIEU, Pierre. A distinção: crítica social do julgamento. Tradução Daniela Kern; Guilherme J. F. Teixeira. São Paulo: Edusp; Porto Alegre, RS: Zouk, 2007.

BYUNG-CHUL, Han. No enxame: perspectivas do digital. Tradução Lucas Machado. Petrópolis, RJ: Vozes, 2018.

CHAUI, Marilene. Convite à filosofia. 14. ed. 4. reimpr. São Paulo: Ática, 2012.

Cultura e democracia: o discurso competente e outras falas. 13. ed. São Paulo: Cortez, 2011.

. O que é ideologia. São Paulo: Brasiliense, 2017.

COIMBRA, Cecilia Maria Bouças; NASCIMENTO, Maria Livia do. O Efeito Foucault: Desnaturalizando Verdades, Superando Dicotomias. Psic.: Teor. e Pesq. vol.17 no.3 Brasília Sept. 2001. Disponível em: <http://dx.doi.org/10.1590/S010237722001000300006>. Acesso em: 25 ago. 2020.

DOUGLAS, Mary; ISHERWOOD, Baron. O mundo dos bens. Tradução Plínio Dentzien. 1. ed. 2. reimpr. Rio de Janeiro: Editora UFRJ, 2009.

FOUCAULT, Michel. Microfísica do poder. Tradução Roberto Machado. (Org.). Rio de Janeiro: Graal, 2001.

RC: 105379

Disponível em: https://www.nucleodoconhecimento.com.br/psicologia/comportamento-de$\underline{\text { consumo }}$ 
. História da loucura na idade clássica. Tradução José Teixeira Coelho Netto. São Paulo: Perspectiva, 2019.

FREUD, Sigmund. Edição Standart Brasileira das Obras Psicológicas Completas de Sigmund Freud. Rio de Janeiro: Imago, 1972.

Obras completas, volume 16: o eu e o id, "autobiografia" e outros textos (19231925). Tradução de Paulo César de Souza. São Paulo: Companhia das Letras, 2011.

HALL, Robert Vance. Manipulação do comportamento: modificação de comportamento (princípios básicos). Tradução Waldir Bettoi. São Paulo: EPU, Editora da Universidade de São Paulo, 1975.

MOREIRA, Márcio Borges; MEDEIROS, Carlos Augusto de. Princípios básicos de análise do comportamento. Porto Alegre: Artmed, 2007.

SAFATLE, Vladimir Pinheiro. Lacan. São Paulo: Publifolha, 2007.

SKINNER, Burrhus Frederic. Ciência e Comportamento Humano. São Paulo: Martins Fontes, 2000.

ZIMERMAN, David E. Manual de técnica psicanalítica: uma re-visão. Porto Alegre: Artmed, 2004.

Enviado: Julho, 2021

Aprovado: Janeiro, 2022.

RC: 105379

Disponível em: https://www.nucleodoconhecimento.com.br/psicologia/comportamento-deconsumo 